\title{
EXTRATO DE Passiflora edulis NA CICATRIZAÇÃO DE FERIDAS CUTÂNEAS ABERTAS EM RATOS: ESTUDO MORFOLÓGICO E HISTOLÓGICO ${ }^{1}$
}

\author{
Extract from Passiflora edulis on the healing of open wounds in rats: morphometric and \\ histological study
}

\begin{abstract}
Inaldo de Castro Garros ${ }^{3}$, Antonio Carlos L. Campos ${ }^{4}$, Elizabeth Milla Tâmbara ${ }^{4}$, Sérgio Bernardo Tenório ${ }^{4}$,Orlando Jorge Martins Torres ${ }^{2}$, Miguel Ângelo Agulham ${ }^{4}$, Allan Cezar Faria Araújo ${ }^{6}$, Paola Maria Brolin Santis-Isolan ${ }^{6}$, Rohnelt Machado de Oliveira ${ }^{6}$, Elaine Cristina de Moraes Arruda ${ }^{5}$
\end{abstract}

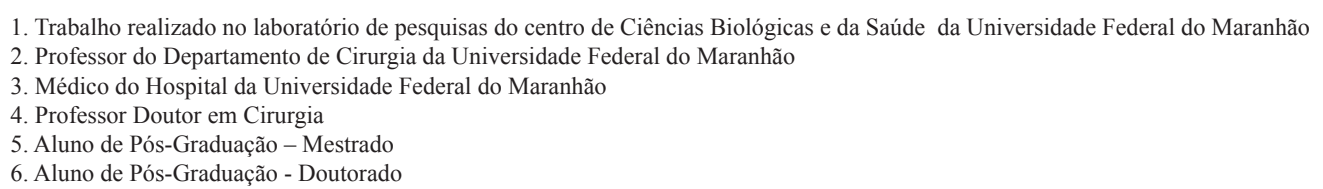

\section{RESUMO}

Introdução: Nas regiões interioranas do Brasil o cataplasma feito com folhas de Passiflora edulis tem sido usado pela população como cicatrizante, para tratar infecções e inflamações cutâneas, sem a comprovação científica dos seus potenciais benefícios. Objetivo: Avaliar a cicatrização de feridas abertas em ratos com a aplicação tópica de extrato hidroalcoólico de Passiflora edulis. Métodos: Foram utilizados 60 ratos da linhagem Wistar, machos, adultos, divididos em dois grupos: o grupo Passiflora e o grupo Controle. Os animais do primeiro grupo foram tratados com o extrato de Passiflora edulis, e os do segundo grupo, com água destilada. A aplicação diária do extrato e da água destilada foi realizada sobre ferida circular padronizada de $2 \mathrm{~cm}$ de diâmetro na região dorsal de cada animal. A avaliação da ferida foi feita do ponto de vista macro e microscópico nos períodos pré-determinados $\left(7^{\circ}, 14^{\circ}\right.$ e $21^{\circ}$ dias). Fez-se a análise macroscópica da evolução do aspecto da lesão e medida da retração cicatricial da ferida, por planimetria digital. O estudo histológico em lâminas coradas pela Hematoxilina-Eosina e Tricômico de Masson considerou os parâmetros de elementos celulares inflamatórios incluindo colagenização e reepitelização. Resultados: Não houve diferença estatisticamente significante entre as áreas cirúrgicas das feridas tratadas com Passiflora edulis e o grupo Controle; entretanto, histologicamente houve colagenização significantemente maior no $14^{\circ}$ dia de pós-operatório nos animais do grupo Passiflora $(\mathrm{p}=0,012)$. Conclusões: O uso tópico do extrato de Passiflora edulis não apresenta macroscopicamente efeito significativo na cicatrização de feridas na pele de ratos; entretanto microscopicamente apresenta aumento da proliferação fibroblástica no $7^{\circ}$ dia e colagenização maior no $14^{\circ}$ dia de pós-operatório.

Descritores: Passiflora edulis. Cicatrização de Feridas. Ratos.

\begin{abstract}
Introduction: In Brazilian countryside, cataplasm made from Passiflora edulis leaves has been used by the population as a healing agent for infections and skin inflammations in an empiric basis. Purpose: the aim of this work was to evaluate the healing process of open wounds in rats, in which Passiflora edulis hydro-alcoholic extract was applied. Methods: Sixty male, adult Wistar rats were divided into two groups: Passiflora group and Control group. Rats of the first group were treated with Passiflora edulis extract, and those of the second group received distilled water. The daily application of the extract or distilled water was carried out on a $2 \mathrm{~cm}$ diameter standardized circular wound on the dorsal region of each animal. Wound assessment was performed macroscopically and microscopically on the $7^{\text {th }}, 14^{\text {th }}$, and $21^{\text {st }}$ postoperative days. Microscopic analysis included hematoxylin-eosine and Masson Trichromium stains, evaluating inflammatory response, fibroplasia and collagen deposition. The wound retraction was evaluated by digital planimetry. Results: No significant difference in the rate of wound healing was detected comparing both groups. However, a significant increase in the number of fibroblastic cells was seen on the $7^{\text {th }}$ PO day, and significantly greater collagen deposition was observed on the $14^{\text {th }}$ day PO day in rats from the Passiflora group $(\mathrm{p}=0,012)$. Conclusions: The application of the Passiflora edulis extract does not accelerate the healing process of open wounds in rats, but is associated with increased number of fibroblastic cells on $7^{\text {th }}$ P.O. day and greater collagen deposition on the $14^{\text {th }} \mathrm{PO}$ day.
\end{abstract}

Key Words: Passiflora edulis. Wound Healing. Rats 


\section{Introdução}

A cicatrização constitui conjunto dinâmico de alterações teciduais importantes na manutenção da integridade do organismo, que envolve inflamação, quimiotaxia, proliferação celular, diferenciação e remodelação ${ }^{1}$.Surge como resposta tecidual às lesões, sejam induzidas por traumatismo ou por procedimentos cirúrgicos. É componente necessário ao processo de reparação, por proporcionar os mecanismos pelos quais o tecido lesado é preparado para a reconstrução ${ }^{2}$. Este fenômeno é usualmente multimediado, localizado, transitório e autolimitado. No entanto, quando o estímulo inflamatório não pode ser eliminado ou removido, desencadeia-se resposta complexa, envolvendo todo o organismo e levando a processo inflamatório crônico, o qual muitas vezes pode ser deletério ${ }^{3}$.

Apesar da predominância, no arsenal terapêutico, de substâncias sintéticas, inclusive as antiinflamatórias, nos últimos anos têm-se verificado retomada à valorização de práticas terapêuticas consideradas por muitos profissionais de saúde como populares ou não científicas, inclusive a lenta reincorporação das ervas medicinais como alternativa ou complemento terapêutico. Vários foram os fitoterápicos testados e usados no processo de cicatrização de feridas cutâneas que se mostraram promissoras. A Aloe Vera (babosa) foi eficaz no tratamento de feridas cutâneas abertas em ratos diabéticos e normais ${ }^{3}$. O extrato alcóolico de flores de Ixora coccinea facilitou os fatores da cicatrização, como aumento da granulação, força de tensão e deposição de colágeno em feridas cutâneas abertas em ratos ${ }^{4}$. O uso tópico da solução de Papaína a 2\% também apresentou bons resultados em feridas cutâneas abertas em ratos ${ }^{5}$.

O maracujá é fruto de numerosas espécies da família Passifloraceae, originária das regiões tropicais e subtropicais do continente americano. A mais comum delas é a Passiflora edulis, conhecida como maracujá amarelo. Esta espécie é bastante cultivada, tanto pelo fruto saboroso como pela beleza de suas flores ornamentais. Na forma de infuso de folhas é usada pela população para combater ansiedade, insônia, epilepsia, febre, cefaléia, neuralgia, tosse, asma, diarréia e dor abdominal.

Outra forma de aplicação clínica da Passiflora edulis é seu preparo como cataplasma e loção, usado para tratar infecções e inflamações cutâneas. A despeito do seu uso freqüente pela população, não foram identificados estudos científicos avaliando sua possível eficácia quando aplicado localmente em feridas abertas.

O presente estudo tem por objetivo avaliar a cicatrização de feridas cutâneas abertas em ratos, tratados com uso tópico do extrato de Passiflora edulis mediante análise macro e microscópica do processo cicatricial até o $21^{\circ}$ dia de pós-operatório.

\section{Métodos}

Este estudo foi realizado no Laboratório de Pesquisa do Departamento de Fisiologia e Farmacologia do Centro de Ciências Biológicas e da Saúde da Universidade Federal do Maranhão, São Luis - MA. Neste local os animais foram mantidos durante todo o período experimental e foram coletados os dados para avaliação clínica e histológica. As peças cirúrgicas foram analisadas no Laboratório de Patologia do Instituto Maranhense de Oncologia Aldenora Bello (IMOAB) e foram obedecidos os princípios éticos em experimentação animal preconizados pelo Colégio Brasileiro de Experimentação Animal, COBEA. O estudo foi aprovado pelo Comitê de Ética do Departamento de Cirurgia do Hospital Universitário da UFMA.

\section{Coleta do material botânico e obtenção do extrato}

Folhas íntegras de Passiflora edulis foram coletadas e secadas por duas semanas em temperatura ambiente e após foram catalogado no Herbário Ático Seabra sob nº1155. Em seguida, foram colocadas em estufa de secagem para retirada da umidade em temperatura de $45^{\circ}$ a $50^{\circ} \mathrm{C}$, por 24 horas. Posteriormente as folhas foram submetidas ao processo de moagem no Laboratório do Pavilhão Tecnológico da Universidade Federal do Maranhão (UFMA). Foi obtido um pó de coloração esverdeada, ao qual foi adicionada solução hidroalcoólica a 70\% na proporção de 1:3. A mistura foi agitada manualmente por cinco minutos a cada duas horas durante 12 horas e filtrada em funil de vidro simples e algodão, por três vezes consecutivas. As principais etapas do processo estão representadas na Figura 1.

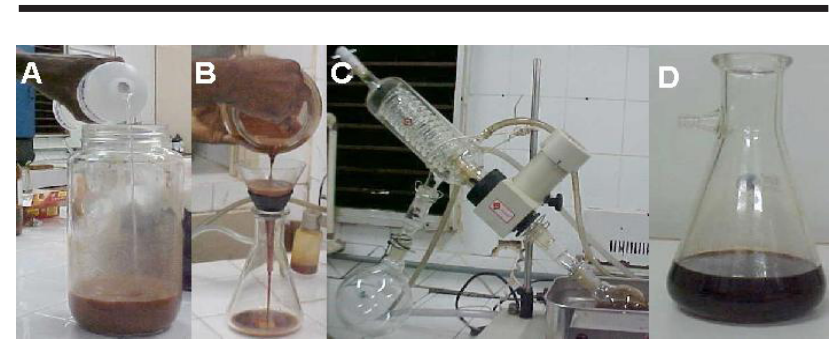

FIGURA 1 - Processo de obtenção do extrato da Passiflora edulis: (a) mistura da solução hidroalcoólica a $70 \%$ ao pó de $P$. edulis; b) filtração da mistura em funil e algodão; c) extrato bruto concentrado em evaporador rotativo para eliminação do solvente; d) extrato bruto de Passiflora edulis de coloração verde-escuro

$\mathrm{O}$ extrato bruto foi concentrado em evaporador rotativo (Fisaton $802^{\circledR}$, São Paulo-SP) em temperatura de $50^{\circ}-55^{\circ} \mathrm{C}$ para a eliminação total do solvente. O material obtido depois da concentração apresentou-se em forma de pasta, sendo desta retiradas as amostras para os testes farmacológicos no Laboratório de Bioquímica do Centro de Ciências Biológica e da Saúde da UFMA. Para uso tópico foram retiradas $20 \mathrm{~g}$ de extrato bruto de Passiflora edulis, diluídas em 100mL de solução salina, o que resultou em concentração final de $200 \mathrm{mg} / \mathrm{mL}$. A sua composição, de acordo com análise bioquímica realizada no Departamento de Análises de Alimentos da UFMA revelou ter: $\mathrm{pH} 5.1$; açúcares totais 19.2\% ; lipídeos 5.24\%; proteínas 9,982\%; cinzas 5,65\%; umidade $58,93 \%$. 


\section{Amostra}

Foram utilizados 60 ratos (Rattus norvegicus albinus, Rodentia mammalia) da linhagem Wistar, machos, adultos, com peso médio de $140 \pm 10 \mathrm{~g}$, procedentes do Biotério Central da Universidade de Campinas (UNICAMP). Permaneceram acondicionados em gaiolas de plástico, em condições de temperatura e umidade ambientais, com livre acesso a água potável e ração industrial própria para ratos (Purina ${ }^{\circledR}$ São Paulo - SP). Respeitou-se o período de aclimatação de sete dias antes do início do experimento.

Os animais foram distribuídos por sorteio, em dois grupos de 30 animais: Grupo P (Passiflora) $(\mathrm{n}=30)$ e Grupo C (Controle) $(\mathrm{n}=30)$

Os grupos foram, por sua vez divididos aleatoriamente em três subgrupos de acordo com o período de observação (7, 14 e 21 dias de pós-operatório), com 10 animais em cada subgrupo.

\section{Anestesia e ato operatório}

Os ratos foram submetidos à anestesia inalatória com éter etílico sob campânula fechada, procedimento proposto por White, e foram considerados anestesiados pela imobilidade do corpo, mas com freqüência e amplitude respiratória normais; em seguida foram identificados com ácido pícrico na cabeça, cauda, lateral direita e esquerda.

Após anestesiados, os animais foram posicionados em decúbito ventral e foram imobilizados em prancha de madeira, com contenção dos membros por tensores elásticos e submetidos a epilação por tração manual na região dorsocostalis em área de aproximadamente $6 \mathrm{~cm}^{2}$.

Para a demarcação da pele a ser retirada, utilizou-se um punch metálico, especialmente confeccionado para este fim, contendo lâmina cortante na sua borda inferior; semelhante ao utilizado nos procedimentos de cirurgia plástica (Figura 2). Com este instrumento, foi excisado fragmento cutâneo de $2 \mathrm{~cm}$ de diâmetro, no centro da área epilada, até a exposição da fáscia muscular dorsal (Figura 3). A hemostasia foi realizada por compressão digital, utilizando-se gaze esterilizada.

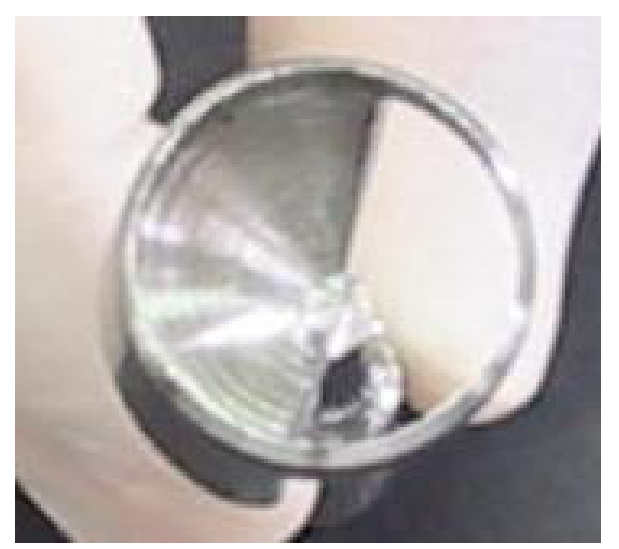

FIGURA 2 - Detalhe do punch metálico utilizado para a marcação da ferida cutânea padronizada

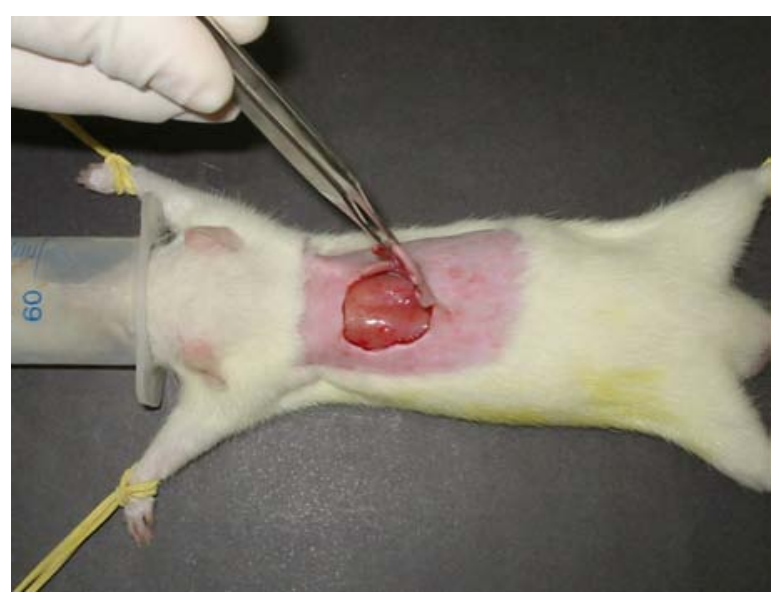

FIGURA 3 - Ato operatório, onde observa-se a exposição da fáscia muscular dorsal

\section{Pós-operatório}

Logo após ao ato operatório, os animais foram reacondicionados nas caixas específicas, divididos de acordo com os seus respectivos grupos, e foi realizada a primeira aplicação tópica de $0,1 \mathrm{~mL}$ do extrato hidroalcoólico de Passiflora edulis na concentração de $200 \mathrm{mg} / \mathrm{mL}$, com seringa de plástico de $1 \mathrm{~mL}$, sem agulha, na ferida cutânea dos ratos. Este procedimento foi repetido diariamente durante sete, 14 ou 21 dias, conforme o subgrupo do grupo Passiflora a que pertencia o animal. No grupo Controle, foi realizado aplicação tópica isovolumétrica de água destilada, diariamente, até a data da morte do animal, semelhante ao realizado no grupo Passiflora. Todos os ratos foram examinados diariamente quanto à sua mobilidade, e foi feita a avaliação macroscópica da ferida operatória, observando-se a presença ou ausência de secreção, crostas ou necrose. Os dados avaliados foram anotados em ficha própria, individual para cada rato.

\section{Planimetria digital}

Todos os animais tiveram suas lesões fotografadas por câmara digital modelo "Power Shot AS100", (Canon ${ }^{\circledR}$, Tokyo, Japão), 1,3 mega pixels, Zoom 3.2. e mantida em tripé a distância constante de $34 \mathrm{~cm}$. Os dados assim obtidos do processo de cicatrização, no $7^{\circ}, 14^{\circ}$ e $21^{\circ}$ dias, foram registrados em protocolo para posterior comparação, por planimetria digital, mediante aplicação do software AUTO CAD 14 (San Rafael, USA).

A avaliação da cicatrização foi realizada em todos os animais mediante a mensuração da área de retração do ferimento, importando-se a imagem da fotografia digital da lesão para o software AUTO CAD 14. Para tanto, o contorno da ferida foi previamente delimitado através do aplicativo POLILINE, que consiste na demarcação de todos os pontos perimetrais pertinentes ao contorno da lesão. O cálculo da área tomou como referência a medida do maior diâmetro, medido com paquímetro digital, e a formatação da figura geométrica em que se transformou o ferimento, expresso em medida decimal. $\mathrm{O}$ cálculo da área foi realizado em 
computador Pentium ${ }^{\circledR}$ III (Intel, USA) (Figura 4).

\section{Morte dos animais e coleta de dados}

No dia pré-estabelecido para a morte (sete, 14 ou 21 dias), os ratos foram pesados e mortos com dose inalatória letal de éter etílico. Em seguida foram fixados à mesa cirúrgica para a coleta de dados morfológicos e do espécime cirúrgico. As feridas operatórias foram examinadas com uso de lupa de 2,5 vezes de aumento para verificação de crostas, secreções, cicatriz hipertrófica e verificado o tamanho da ferida residual no maior e menor eixo, medidos com paquímetro digital (ZEIN ${ }^{\circledR}$ - Alemanha).

A ferida foi excisada com margem de $1 \mathrm{~cm}$ de pele íntegra em torno da lesão, em profundidade até a fáscia muscular. Cada peça foi identificada individualmente, fixada em isopor e colocada em solução de formalina a $10 \%$ para em seguida ser encaminhada ao Laboratório de Patologia no Instituto Maranhense de Oncologia do Hospital Aldenora Bello, onde foram confeccionadas as lâminas para a avaliação histológica.

\section{Avaliação microscópica}

As peças retiradas foram conservadas em formalina $10 \%$ por 48 horas e posteriormente inclusas em parafina, submetidas a cortes transversais de $4 \mu$, com micrótomo, e coradas com hematoxilina-eosina (HE), para avaliação global dos cortes de tecido, e pelo Tricômico de Masson (TM), para avaliar a presença de fibras colágenas existentes nos locais de fibrose do interstício.

A análise dos cortes histológicos foi realizada pelo mesmo patologista sem o conhecimento prévio da identificação dos grupos. Os dados obtidos pela técnica de HE foram classificados de acordo com a intensidade em que foram encontrados e transformados em variáveis quantitativas mediante atribuição de índice para o achado histológico, conforme demonstrados no Quadro 1.

A intensidade dos achados de HE e TM foi analisada segundo os seguintes critérios:

Proliferação Vascular - foi considerada ausente, quando não se evidenciava vasos no corte histológico; discreta, quando eram visibilizados poucos vasos esparsamente situados, de forma isolada no contexto; moderada, quando apareciam com maior freqüência e dispersos no campo óptico e acentuada, quando evidenciados com grande freqüência, dispostos em todo o contexto.

Células mononucleares - foram classificadas em ausente, quando estas células não eram visualizadas no campo óptico; discreta, quando evidenciadas de forma isolada, possibilitando distinguir áreas livres de infiltrado; moderada quando apareciam com maior freqüência, constituindo agregados densos, mas possibilitando visualizar áreas livres de infiltrado; e acentuada, quando as células foram evidenciadas com grande freqüência, constituindo agregados densos e justapostos, sem áreas livres de infiltrados.

Células polimorfonucleares - foram classificadas em ausentes, quando ainda não eram visibilizadas no campo óptico; discretas, quando eram visibilizadas esparsamente, de forma isolada, com muitas áreas livres de infiltrados; moderada, quando já eram visibilizadas formando agregados, porém com áreas adjacentes livres de infiltrados; acentuada, quando estas células apareciam com grande freqüência, formando agregados densos, sem áreas livres de infiltrados.

Proliferação fibroblástica - foi classificada em ausente, quando não se evidenciava proliferação de fibroblastos; discreta, quando havia esparsos fibroblastos proliferados em meio a tecido conjuntivo frouxo; moderada, quando havia moderada quantidade de fibroblastos proliferados, constituindo pequenos feixes celulares multi-direcionalmente; e intensa, quando havia grande quantidade de fibroblastos proliferados constituindo agregados compactos de células arranjadas multi-direcionalmente.

Colagenização - classificou-se como ausente, quando não havia fibras colágenas depositadas; discreta, quando a deposição de fibras colágenas era em pequena quantidade, caracterizadas por fibras depositadas em meio aos fibroblastos proliferados; moderada quando a deposição de colágeno formava feixes de fibras eosinofílicas, espessas, intercaladas com áreas de tecido conjuntivo frouxo e fibroblastos proliferados; e intensa, quando havia grande deposição de fibras colágenas, constituindo feixes de fibras eosinofílicas espessas, compactamente arranjadas em meio a fibroblastos proliferados e sem áreas de tecido conjuntivo frouxo.

Reepitelização - classificou-se como ausente, quando não havia epitélio visibilizado no campo óptico; discreto ou moderado, quando aparecia de forma incompleta ou parcial; acentuada, quando visibilizado de forma total ou completa sobre o tecido conjuntivo.Os dados coletados foram registrados em fichas individuais para cada animal.

\section{Análise estatística}

Os dados foram analisados utilizando-se o programa Statistics for Windows 5.1. A variável numérica, área cirúrgica $\left(\mathrm{cm}^{2}\right)$, foi avaliada pelo teste $t$ de Student. A avaliação

QUADRO 1 - Classificação e atribuição de índices aos achados histológicos de HE (Hematoxilina - Eosina) e TM (Tricrômio de Masson)

\begin{tabular}{|c|c|c|c|c|}
\hline \multirow{2}{*}{ Achados HE/TM } & \multicolumn{4}{|c|}{ Intensidade dos achados } \\
\hline & Ausente & Discreto & Moderado & Acentuado \\
\hline Proliferação vascular & 0 & 1 & 2 & 3 \\
\hline Células mononucleares & 0 & 1 & 2 & 3 \\
\hline Células Polimorfonucleares & 0 & 1 & 2 & 3 \\
\hline Proliferação fibroblástica & 0 & 1 & 2 & 3 \\
\hline Colagenização & 0 & 1 & 2 & 3 \\
\hline Reepitelização & 1 & 2 & 2 & 3 \\
\hline
\end{tabular}


conjunta dos efeitos dos grupos Controle (C) e Passiflora (P), e dos dias (7, 14 e 21), bem como da interação entre eles, foi feita pelo teste ANOVA com dois fatores. A comparação entre as médias foi feita pelo teste de Tukey. As variáveis da avaliação histológica foram analisadas pelo teste não-paramétrico de Mann-Whitney. A análise inter-grupo foi feita pelo teste não paramétrico de Kruskal-Wallis. O nível de significância utilizado para se rejeitar a hipótese de nulidade foi de $5 \%(p<0,05)$.

\section{Resultados}

Evolução pós-operatória e exame da ferida

O ato operatório de todos os animais transcorreu sem

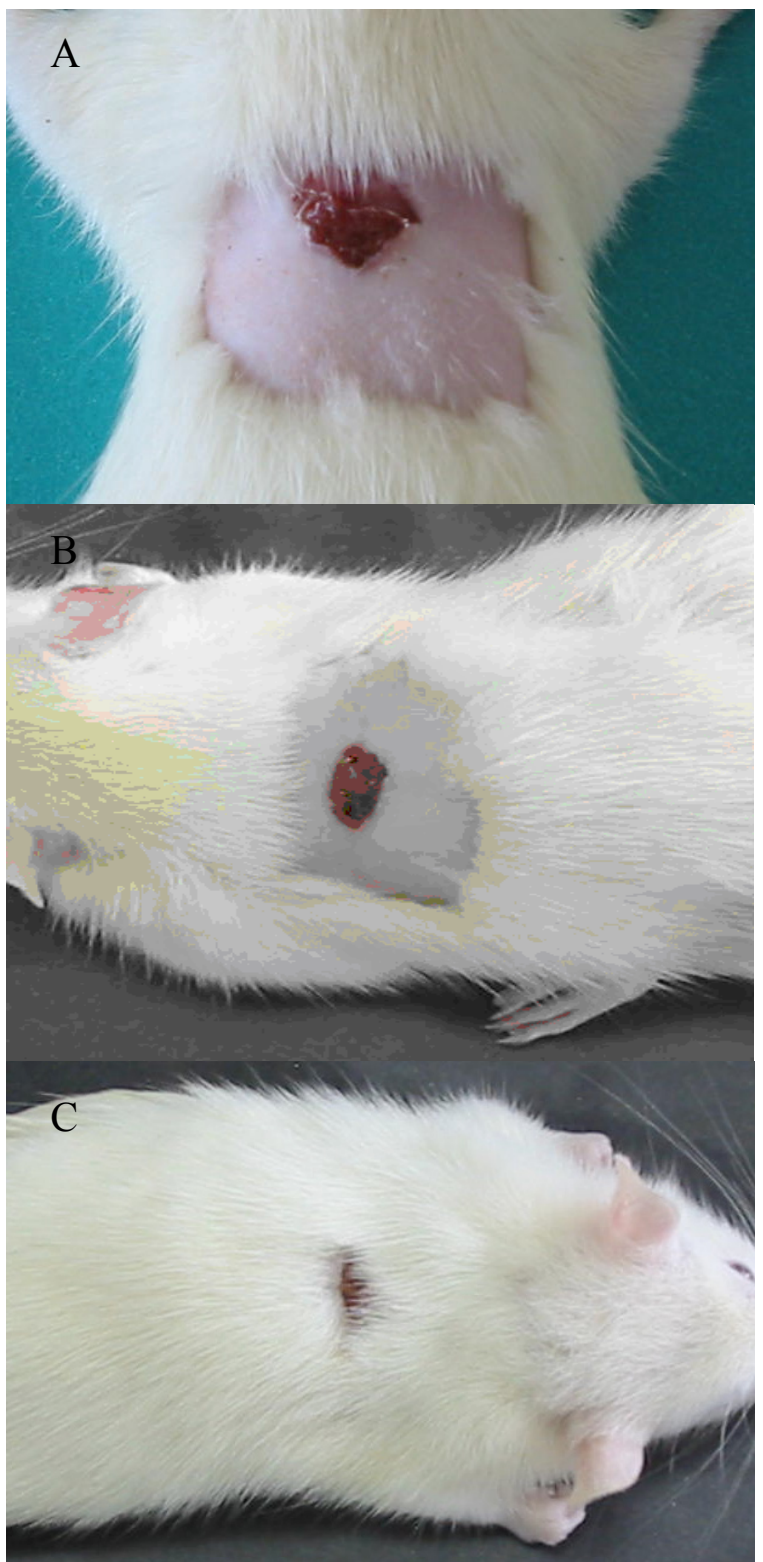

FIGURA 4 - Fotos comparativas de animais do grupo Passiflora mostrando as lesões no $7^{\circ}(\mathrm{A}), 14^{\circ}$ (B) e $21^{\circ}$ dia (C) de pós-operatório complicações. Não houve óbitos. Todos os ratos recuperamse bem da anestesia. As avaliações clínicas diárias mostraram adequada recuperação, com manutenção do estado geral, presença de atividade física e disposição para alimentar-se no grupo Controle e grupo Passiflora.

A evolução da ferida cutânea nos ratos do grupo Controle e no grupo Passiflora mostrou exsudação e formação de crostas delicadas até o $7^{\circ}$ dia de pós-operatório. A partir do $7^{\circ}$ dia, houve espessamento da crosta, que passou a destacar-se espontaneamente a partir do $14^{\circ}$ dia; evoluindo para epitelização no $21^{\circ}$ dia de pós-operatório, com crescimento de pelos em torno da lesão (Figuras 4 e 5).
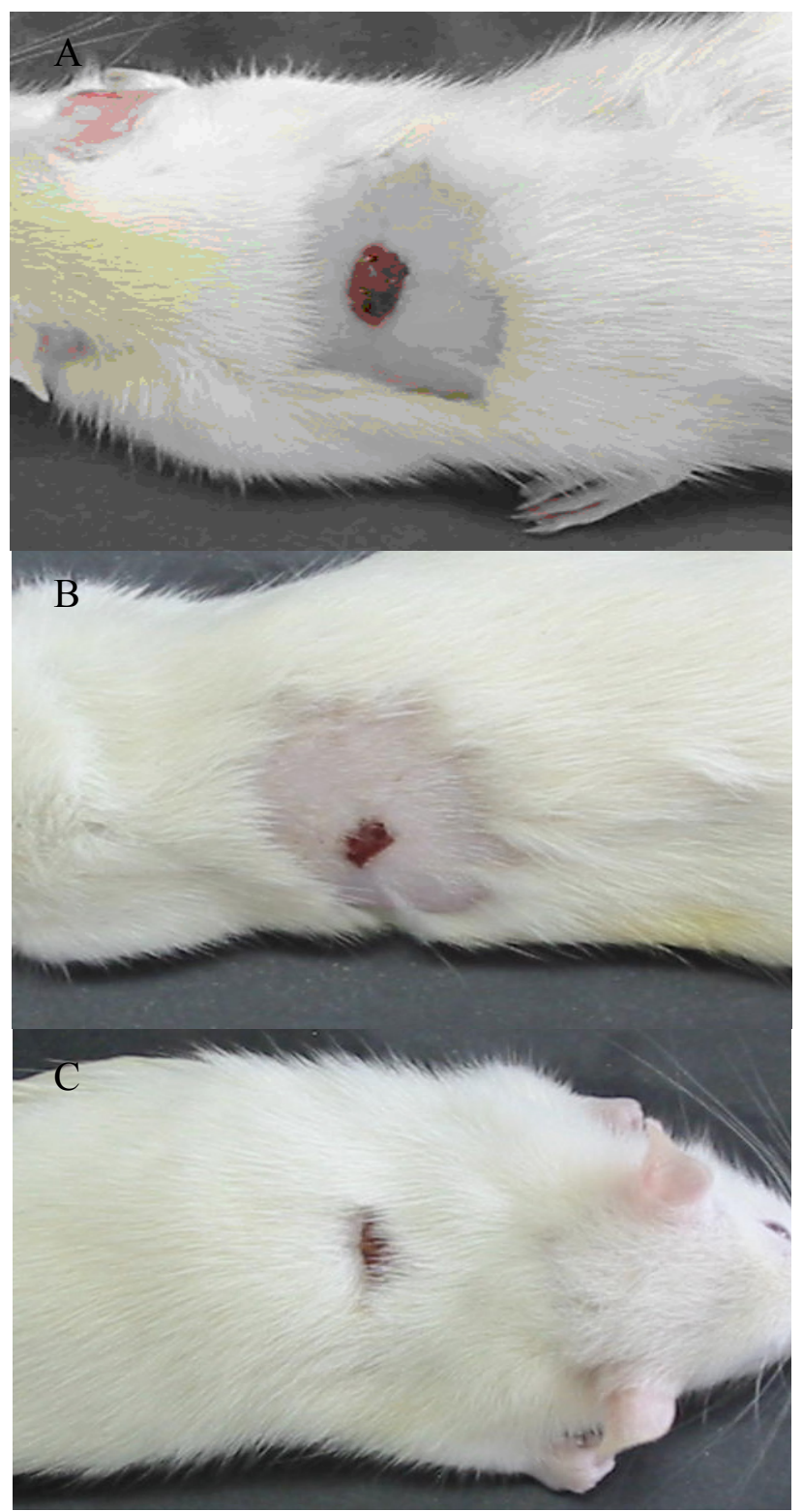

FIGURA 5 - Fotos comparativas de animais do grupo controle mostrando as lesões no $7^{\circ}(\mathrm{A}), 14^{\circ}(\mathrm{B})$ e $21^{\circ}$ (C) de observação do pós-operatório 
Evolução da área da ferida

Aárea da ferida diminuiu gradativamente com a evolução do tempo. A média e o desvio padrão para cada subgrupo estão demonstrados na Tabela 1 e representados na Figura 6. Como pode ser observado nesta tabela, as áreas das feridas diminuíram progressivamente de maneira significativa em ambos os grupos com a evolução. Entretanto, quando os grupos foram comparados entre si as médias das áreas foram similares entre os grupos Controle e Passiflora no $7^{\circ}, 14^{\circ} \mathrm{e}$ $21^{\circ}$ dias de pós-operatório.

\section{Avaliação microscópica}

\section{Reação inflamatória aguda}

\section{1.a. Proliferação vascular}

Os resultados da análise da proliferação vascular estão relatados na Tabela 2. Não foram detectadas diferenças significantes em nenhum dos períodos estudados.

TABELA 1 - Média e desvio-padrão da área cirúrgica dos ratos entre os grupos controle (C) e Passiflora (p) no 7o, 14o e 21o dias de pós-operatório

\begin{tabular}{lcccc}
\hline \multirow{2}{*}{ Grupos } & \multicolumn{3}{c}{ Dias } & Análise do tempo \\
\cline { 2 - 4 } & $\mathbf{7}$ & $\mathbf{1 4}$ & $\mathbf{2 1}$ & A \\
\hline Controle & $1,469 \pm 0,38^{\mathrm{a}}$ & $0,098 \pm 0,11^{\mathrm{b}}$ & $0,000 \pm 0,00^{\mathrm{c}}$ & ${ }^{*} \mathrm{p}=0,000$ \\
Passiflora & $1.269 \pm 0,48^{\mathrm{a}}$ & $0,095 \pm 0,09^{\mathrm{b}}$ & $0,036 \pm 0,10^{\mathrm{c}}$ & $*{ }^{*} \mathrm{p}=0,000$ \\
Análise & 0,316 & 0,951 & $0,9510,271$ & \\
intergrupo & & & \\
\hline
\end{tabular}

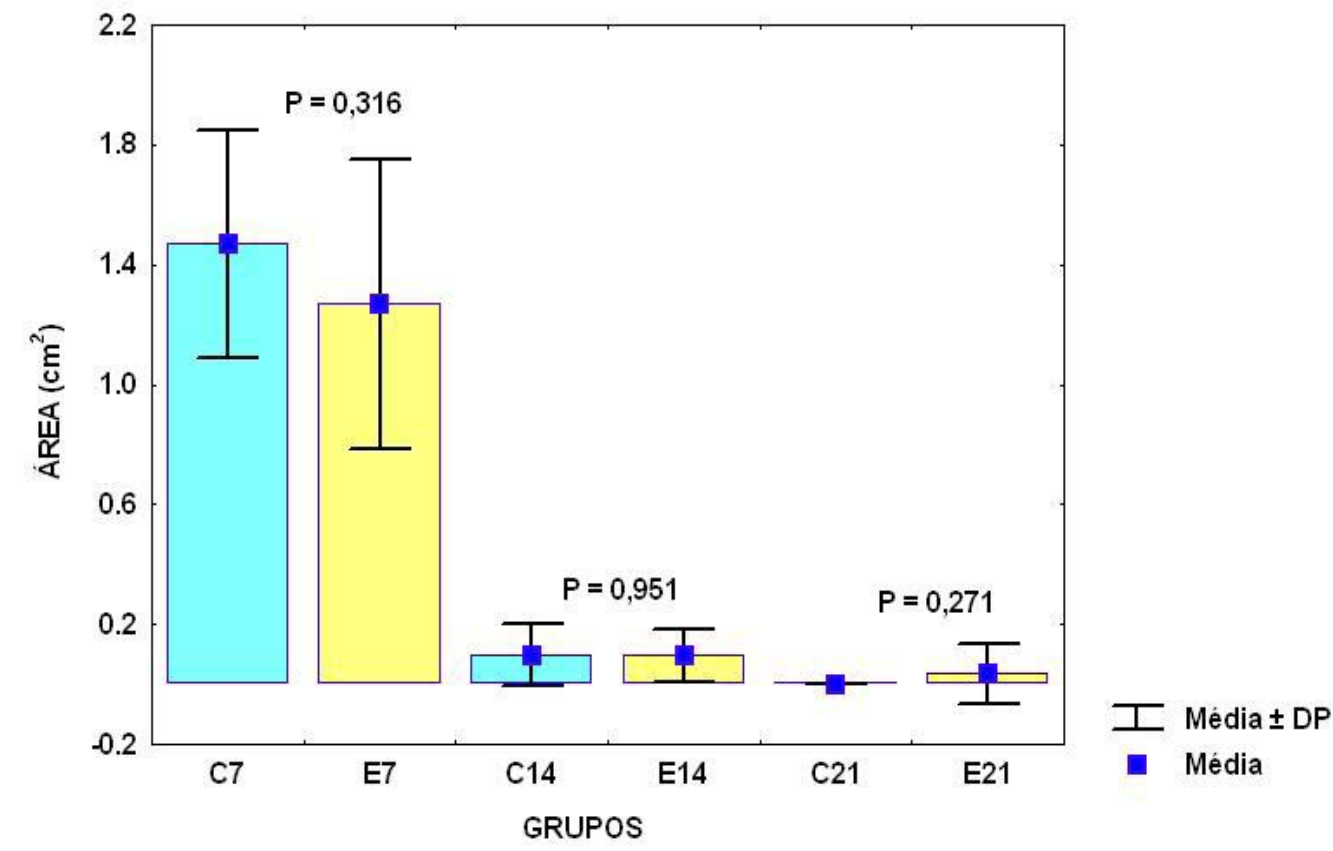

FIGURA 6 - Média, desvio padrão e significância estatística da área cirúrgica dos subgrupos C7, P7, C14, P14, C21 E $\mathrm{P} 21$.

TABELA 2 - Intensidade da inflamação aguda com avaliação da proliferação vascular observados na fase de reparação tecidual

\begin{tabular}{|c|c|c|c|c|c|c|}
\hline & \multicolumn{2}{|c|}{$7^{0}$ Dia } & \multicolumn{2}{|c|}{$14^{\circ} \mathrm{Dia}$} & \multicolumn{2}{|c|}{$21^{\circ}$ Dia } \\
\hline & C & $\mathbf{P}$ & C & $\mathbf{P}$ & C & $\mathbf{P}$ \\
\hline Ausente & 0 & 0 & 0 & 0 & 0 & 0 \\
\hline Discreta & 0 & 0 & 7 & 8 & 9 & 10 \\
\hline Moderada & 2 & 6 & 3 & 2 & 1 & 0 \\
\hline Acentuada & 8 & 4 & 0 & 0 & 0 & 0 \\
\hline
\end{tabular}




\section{1.b. Polimorfonucleares}

A intensidade da inflamação aguda, avaliada pela presença de células polimorfonucleares está apresentada na Tabela 3. Não foram observadas diferenças significativas entre os grupos. Na Figura 7 encontra-se representada a infiltração de polimorfonucleares em um rato do grupo Passiflora.

\section{1.c.Células mononucleares}

Com relação à presença de células mononucleares, no $7^{\mathrm{o}}$ dia de pós-operatório, elas foram classificadas como moderadas em oito animais e acentuadas em dois animais do grupo Controle; discretas em oito animais e moderadas em dois animais do grupo Passiflora. Houve diferença estatisticamente significante entre os grupos.

No $14^{\circ}$ dia de pós-operatório, as células mononucleares foram classificadas como ausentes em um animal, discretas em dois animais e moderadas em cinco animais do grupo Controle; foram discretas em dois animais e moderadas em oito do grupo Passiflora. Houve diferença marginalmente significativa entre os grupos. Já no $21^{\circ}$ dia de pós-operatório, não houve diferença estatisticamente significante entre os grupos. Estes resultados estão apresentados na Tabela 4. A Figura 8 representa exemplos da infiltração por células mononucleares.

\section{Reação inflamatória crônica}

\section{2.a. Proliferação fibroblástica}

Com relação à reação inflamatória crônica, avaliada pela proliferação fibroblástica, no $7^{\circ}$ dia de pós-operatório, ela foi discreta em nove e moderada em um animal do grupo Controle; foi classificada como discreta em nove e moderada em um animal do grupo Passiflora. Esta diferença foi estatisticamente significante $(\mathrm{p}=0,000)$ entre os grupos. No $14^{\circ}$ e $21^{\circ}$ dias não houve diferença entre os grupos, conforme relatado na Tabela 5 .

TABELA 3 - Intensidade da inflamação aguda com avaliação de polimorfonucleares observados no processo de reparação tecidual

\begin{tabular}{|c|c|c|c|c|c|c|}
\hline & \multicolumn{2}{|c|}{$7^{\circ}$ Dia } & \multicolumn{2}{|c|}{$14^{\circ}$ Dia } & \multicolumn{2}{|c|}{$21^{\circ}$ Dia } \\
\hline & C & $\mathbf{P}$ & $\mathrm{C}$ & $\mathbf{P}$ & $\mathrm{C}$ & $\mathbf{P}$ \\
\hline Ausente & 0 & 0 & 6 & 6 & 10 & 10 \\
\hline Discreta & 0 & 0 & 2 & 4 & 0 & 0 \\
\hline Moderada & 2 & 0 & 2 & 0 & 0 & 0 \\
\hline Acentuada & 8 & 10 & 0 & 0 & 0 & 0 \\
\hline & \multicolumn{2}{|c|}{$\mathrm{p}=0,068$} & \multicolumn{2}{|c|}{$\mathrm{p}=0,35$} & \multicolumn{2}{|c|}{$\mathrm{p}=1$} \\
\hline
\end{tabular}

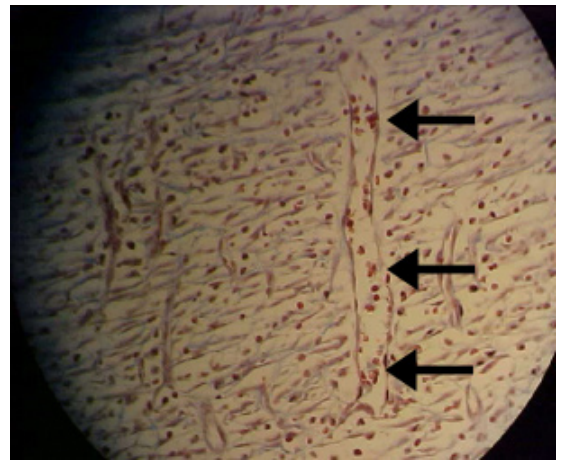

FIGURA 7 - Fotomicrografia da ferida cirúrgica com uso do extrato de Passiflora edulis no $7^{\circ}$ dia de pósoperatório. Observa-se acentuada intensidade de polimorfonucleares no campo óptico (M.O, coloração H.E., aumento de 40x)

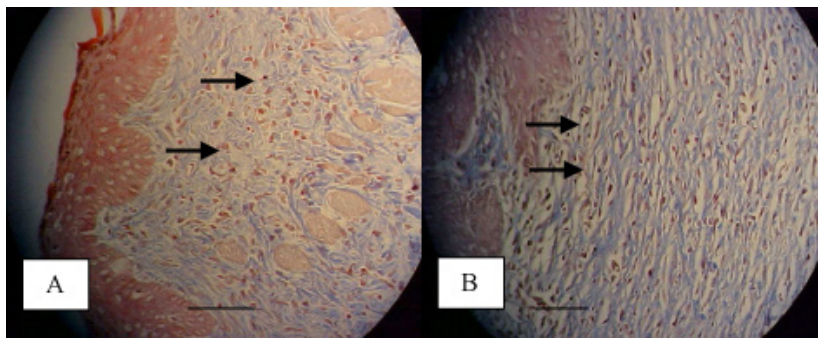

FIGURA 8 - Fotomicrografia do tecido de reparação da pele de rato do grupo Passiflora no $7^{\circ}$ dia de pós-operatório (A) e no $14^{\circ}$ dia de pós-operatório (B). observa-se células (setas) mononucleares em intensidades moderada e acentuada nos campos ópticos, respectivamente (M.O, coloração H.E. aumento de 40x)

TABELA 4 - Intensidade da inflamação aguda com avaliação de mononucleares observados no processo de reparação tecidual

\begin{tabular}{|c|c|c|c|c|c|c|}
\hline & \multicolumn{2}{|c|}{$7^{\circ}$ Dia } & \multicolumn{2}{|c|}{$14^{\circ}$ Dia } & \multicolumn{2}{|c|}{$21^{\circ}$ Dia } \\
\hline & C & $\mathbf{P}$ & C & $\mathbf{P}$ & $\mathrm{C}$ & $\mathbf{P}$ \\
\hline Ausente & 0 & 0 & 1 & 0 & 0 & 1 \\
\hline Discreta & 0 & 8 & 2 & 2 & 9 & 9 \\
\hline Moderada & 8 & 2 & 5 & 8 & 1 & 0 \\
\hline Acentuada & 2 & 0 & 0 & 0 & 0 & 0 \\
\hline
\end{tabular}




\section{2.b. Colagenização}

A colagenização foi similar entre os grupos no $7^{\circ}$ dia de pós-operatório, conforme demonstrado na Tabela 6 . Entretanto, no $14^{\circ}$ dia de pós-operatório a colagenização foi discreta em 10 animais do grupo controle; discreta em cinco e moderada em cinco animais do grupo Passiflora. Houve diferença estatisticamente significante entre os grupos $(\mathrm{p}=$ 0,01). A Figura 9 apresenta exemplo de colagenização em rato do grupo Passiflora.

\section{2. c.Reepitelização}

No $7^{\circ}$ dia de pós-operatório, a reepitelização foi ausente em 10 animais do grupo Controle; ausente em cinco e parcial em cinco animais do grupo Passiflora. Esta diferença foi estatisticamente significante $(\mathrm{p}=0,01)$.

Não foram observadas diferenças significantes na reepitelização no $14^{\circ}$ e no $21^{\circ}$ dia de pós-operatório, conforme pode-se ver na Tabela 7 .

\section{Discussão}

Vários autores já avaliaram o emprego tópico de inúmeros fitoterápicos com o objetivo de influenciar o processo cicatricial, com resultados variados. Contrera et al3, estudaram a tintura mãe de raízes de Lichnophora ericoides (arnica-da-serra-dourada), de Aristolochia esperanzae (papode-perú) e de Solidago microglossa (falsa-arnica) em feridas cutâneas de ratos. Houve retardo na cicatrização das feridas submetidas ao tratamento com a tintura, com relação ao controle. Marchini et al. ${ }^{6}$ avaliaram o uso da Rosa. Rubiginosa L., (Óleo de Rosa Mosqueta) em ferimentos cutâneos no dorso de ratos. $\mathrm{O}$ óleo mostrou-se eficaz no tratamento de feridas abertas em animais de laboratório, acelerando a cicatrização. Sanchez et al. ${ }^{5}$ estudaram aspectos morfológicos e morfométricos da reparação tecidual de feridas cutâneas em ratos com ou sem tratamento com solução de papaína a $2 \%$. O seu uso promoveu reparação tecidual mais eficaz que o grupo Controle, atuando na fase inicial e de fibroplasia das feridas tratadas.

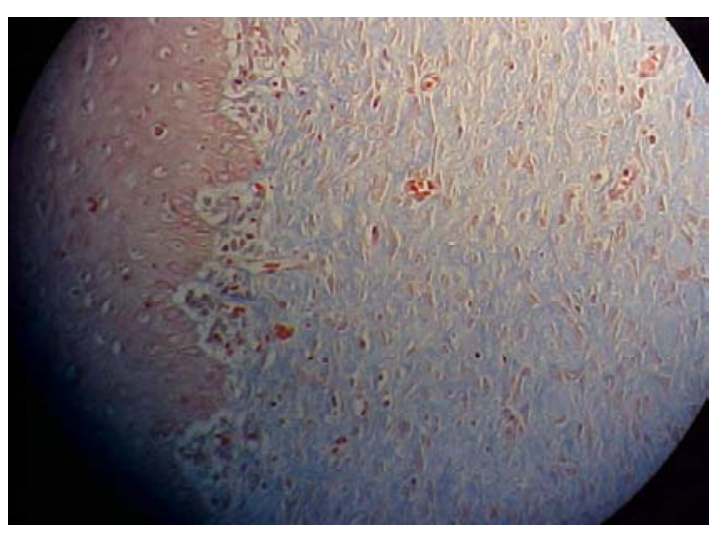

FIGURA 9 - Fotomicrografia da ferida cirúrgica com uso do extrato da Passiflora edulis no $14^{\circ}$ dia de pósoperatório. Observa-se colagenização moderada (M.O. coloração T.M., aumento de 40x)

TABELA 5 - Intensidade da inflamação crônica com avaliação da proliferação fibroblástica observada no processo de reparação tecidual

\begin{tabular}{cccccccc}
\hline & \multicolumn{3}{c}{$\mathbf{7}^{\mathbf{0}} \mathbf{D i a}$} & \multicolumn{2}{c}{$\mathbf{1 4}^{\mathbf{0}} \mathbf{D i a}$} & \multicolumn{2}{c}{$\mathbf{2 1}^{\mathbf{0}} \mathbf{D i a}$} \\
\cline { 2 - 8 } & $\mathbf{C}$ & $\mathbf{P}$ & $\mathbf{C}$ & $\mathbf{P}$ & $\mathbf{C}$ & $\mathbf{P}$ \\
\hline Ausente & 0 & 0 & 0 & 0 & 0 & 0 \\
Discreta & 9 & 0 & 0 & 0 & 0 & 0 \\
Moderada & 1 & 8 & 4 & 4 & 1 & 0 \\
Acentuada & 0 & 2 & 6 & 6 & 9 & 10 \\
\hline
\end{tabular}

TABELA 6 - Intensidade da inflamação crônica com avaliação da colagenização observada no processo de reparação tecidual

\begin{tabular}{|c|c|c|c|c|c|c|}
\hline & \multicolumn{2}{|c|}{$7^{0}$ Dia } & \multicolumn{2}{|c|}{$14^{\circ} \mathrm{Dia}$} & \multicolumn{2}{|c|}{$21^{\circ}$ Dia } \\
\hline & C & $\mathbf{P}$ & C & $\mathbf{P}$ & C & $\mathbf{P}$ \\
\hline Ausente & 4 & 1 & 0 & 0 & 0 & 0 \\
\hline Discreta & 6 & 9 & 10 & 5 & 1 & 2 \\
\hline Moderada & 0 & 0 & 0 & 5 & 8 & 6 \\
\hline Acentuada & 0 & 0 & 0 & 0 & 1 & 2 \\
\hline
\end{tabular}

TABELA 7 - Intensidade da inflamação crônica com avaliação da reepitelização, observada no processo de reparação tecidual

\begin{tabular}{|c|c|c|c|c|c|c|}
\hline & \multicolumn{2}{|c|}{$7^{0}$ Dia } & \multicolumn{2}{|c|}{$14^{\circ} \mathrm{Dia}$} & \multicolumn{2}{|c|}{$21^{\circ}$ Dia } \\
\hline & C & $\mathbf{P}$ & $\mathrm{C}$ & $\mathbf{P}$ & C & $\mathbf{P}$ \\
\hline Ausente & 10 & 5 & 0 & 0 & 0 & 0 \\
\hline Parcial & 0 & 5 & 2 & 2 & 0 & 4 \\
\hline Completa & 0 & 0 & 8 & 8 & 10 & 6 \\
\hline
\end{tabular}


Eurides et al. ${ }^{7}$ estudaram aspectos morfológicos e morfométricos da evolução cicatricial de feridas cutâneas em dorso de ratos tratadas com solução aquosa de barbatimão (Stryphynodendron barbatiman martius). Os resultados mostraram que esta solução apresentou eficiência significativa no auxílio da reparação cicatricial de feridas cutâneas de camundongos.

Brito et al. ${ }^{8}$. estudaram a influência do extrato aquoso de Centella asiática em ferimento experimentais em ratos albinos. Os resultados mostraram que o extrato aquoso quando em suspensão com propilenoglycol a 5\% favoreceu o processo cicatricial das feridas. Brito ${ }^{8}$ avaliou os aspectos morfológicos e morfométricos da cicatrização de feridas cutâneas abertas em ratos, tratados com óleo de copaíba. Houve retardo no processo de contração da ferida do grupo copaíba em relação ao controle. Miranda ${ }^{9}$ avaliou o uso da tintura de arnica em feridas cutâneas abertas em ratos. Os resultados mostraram retardo na retração cicatricial do grupo arnica, em relação ao controle.

A revisão da literatura médica nas bases de dados da Medline e Lilacs não identificou nenhum trabalho clínico ou experimental que tenha avaliado o extrato etanólico das folhas da Passiflora edulis no processo de cicatrização de ferida aberta no dorso de ratos. Desta forma, pareceu justificável, a realização do presente estudo.

$\mathrm{O}$ animal de escolha foi o rato, da linhagem Wistar, devido à facilidade de manuseio e acomodação, resistência à manipulação, agressões cirúrgicas e a processos infeccio$\operatorname{sos}^{15}$. É também animal amplamente utilizado em estudos experimentais ${ }^{10}$.

A escolha do fitoterápico, mais precisamente, pela utilização das folhas da Passiflora edulis para obtenção do extrato bruto, foi feita por ser um processo bem estabelecido e difundido. Silva ${ }^{11}$ estudou a atividade analgésica de extrato semelhante, tanto pela via oral e como por via intra-peritoneal. Foi constatada a diminuição do número de contorções abdominais induzidas por ácido acético em camundongos; a atividade antiinflamatória foi confirmada pela redução do edema de orelha nestes animais, induzido por óleo de cróton.

Silva ${ }^{11}$, demonstraram que o extrato etanólico das folhas da Passiflora edulis apresenta efeito analgésico e anti-inflamatório, pela redução de números de contorções abdominais em camundongos, assim como a diminuição do edema de orelha desses animais e a redução do edema de pata em ratos. Estes achados sugerem a presença de compostos químicos relacionados com a atividade analgésica e antiinflamatória, característica de antiinflamatórios não esteroidais (AINES), que diminuem a dor por inibição da biossíntese de eicosanóides, mediadores de processos inflamatórios ${ }^{12}$.

Adotou-se no presente estudo os dias sete, 14 e 21 para análise dos parâmetros. Simões et al. ${ }^{13}$ demonstraram que estes são os dias mais significantes para o estudo do processo de reparação tecidual da pele. Existem na literatura, trabalhos sobre cicatrização em feridas cutâneas de ratos em que os períodos de observação foram de sete e 14 dias6; 10 dias $^{3}$; três, sete, 14 e 21 dias $^{5,7}$; quatro, oito, 12, 16, 20 e 24 dias; três, sete e 21 dias $^{8,9}$.

Marchini et al. ${ }^{6}$, estudando o efeito do óleo de rosa mosqueta na cicatrização de feridas abertas em animais de experimentação, constataram diferenças entre os grupos controle e experimento somente a partir do $7^{\circ}$ dia de pósoperatório, motivo pelo qual a observação neste trabalho não incluiu o $3^{\circ}$ dia.

A depilação do dorso dos animais foi feita através de método manual e não mecânico, pelo fato de que a tração manual dos pelos dificilmente causa lesões na pele, ao contrário do que acontece com o uso de aparelhos laminados.

A região dorsal do rato, escolhida para produzir a lesão, teve por finalidade evitar que o próprio animal conseguisse atingi-la, e por ser modelo experimental de ferida aberta bastante conhecido ${ }^{10,14}$. Quanto ao tamanho das lesões, foi utilizada medida constante, o que permitiu melhor acompanhamento da cicatrização, conforme já utilizada por outros autores, como Marchini et al. ${ }^{6}$ e Sanchez Neto et al. ${ }^{5}$.

A ferida operatória foi estudada por observações macro e microscópica nos dias considerados os mais significantes para o estudo do processo de reparação tecidual da pele de $\operatorname{ratos}^{10}$

\section{Avaliação macroscópica}

A morfometria da área cirúrgica foi feita por planimetria digital mediante fotografia digital das lesões. Utilizou-se o programa de computador AUTOCAD 14 (San Rafael-USA) empregado pelos engenheiros civis, no cálculo de área física em topografia. Na evolução cicatricial, a retração dos bordos da lesão deformou seu aspecto original e padronizado pelo que foi utilizado o aplicativo POLILINE empregado para a formatação de qualquer área geométrica a ser definida. $\mathrm{O}$ cálculo, após a definição da área, foi realizado por computador Pentium III (Intel-USA).

Em relação à área da ferida observou-se decréscimo significante ao longo do tempo, acentuadamente entre o $7^{\circ}$ e $14^{\circ}$ dias de pós-operatório tanto para o grupo Controle quanto para o grupo Passiflora. A comparação dos dois grupos de estudo não evidenciou efeito da Passiflora edulis na redução da área cirúrgica com relação ao grupo Controle, visto que as médias estatísticas foram similares nos três períodos de observação. A diferença estatística acentuada entre o $7^{\circ}$ e $14^{\circ}$ dias de pós-operatório indicou apenas efeito temporal.

\section{Avaliação microscópica}

Para a análise histológica foram utilizados dois tipos de coloração: Hematoxilina-Eosina (H.E) e Tricrômio de Masson (T.M). A primeira para observação dos elementos celulares e esta última, para o estudo do colágeno.

O processo de reparação tecidual apresenta várias fases com características próprias, que se desenvolvem concomitantemente $\mathrm{e}^{10,13,15}$.

No $7^{\circ}$ dia de pós-operatório, observou-se que as lesões, tanto no grupo Controle como no Passiflora, apresentavam suas superfícies recobertas por crosta fibrino-leucocitária, de consonância com o que afirmam estudos feitos sobre cicatrização. A solução de continuidade causada pela remoção do fragmento de pele é inicialmente preenchida por coágulo, fibrina e exudato inflamatório ${ }^{10,13,14}$. 
A fase inicial da cicatrização é chamada de inflamatória e é vital para o processo de reparação. Sem inflamação não há reparação6. Ocorre aumento da permeabilidade capilar e consequente migração de células (leucócitos, linfócitos, eritrócitos) para a ferida, que com o acúmulo de plasma, constituem o exsudato inflamatório ${ }^{10,13}$; compatível com o que foi encontrado na análise histológica de ambos os grupos (Controle e Passiflora).

Segue-se então a fase proliferativa ou de fibroplasia. A proliferação endotelial, processo fundamental no mecanismo de cicatrização, depende da presença de macrófagos, que promovem a neo-angiogênese devido às suas interações com prostaglandinas e tromboxanes. Em contigüidade aos capilares rompidos, originam-se brotos endoteliais que proliferam rapidamente, formando cordões sólidos, entremeando-se com os fibroblastos, que se canalizam permitindo o fluxo sanguíneo. O conjuntivo recém formado, intensamente vascularizado, constitui o tecido de granulação ${ }^{15,16}$. A intensa proliferação vascular nesta fase foi compatível com o encontrado neste trabalho. A comparação entre os grupos Controle e Passiflora não mostrou diferença significativa entre os grupos.

Em relação ao número de leucócitos (mononucleares e polimorfonucleares), a variância por postos de KruskalWallis mostrou, tanto para o grupo Controle como para o Passiflora, que os valores sofreram decréscimo significante ( $\mathrm{p}=0,0003$ e $\mathrm{p}=0,0005$ respectivamente), pois os valores observados aos 14 e 21 dias de pós-operatório foram significantemente menores que aos sete dias. Quando comparados os dois grupos, pelo teste de Mann-Whitney, houve diferença estatisticamente significante no $14^{\circ}$ dia, em função dos mononucleares. Estes achados estão de acordo com os dizeres de Masini ${ }^{18}$ de que os leucócitos são as primeiras células inflamatórias a aparecerem na área da lesão e tem vida curta.

O fibroblasto é célula reguladora por apresentar a dupla função de síntese e reabsorção de colágeno, procurando manter o equilíbrio quantitativo e qualitativo desta proteína ${ }^{13}$. Os valores obtidos na contagem de fibroblastos mostrou que, no grupo Passiflora, os valores foram máximos aos sete dias de pós-operatório, apresentando decréscimo a partir de então. Achados semelhantes foram obtidos por Alvares ${ }^{18}$ e Simões et al. ${ }^{13}$ o mesmo não ocorrendo com o grupo Controle do experimento. Quando os dois grupos foram comparados entre si, não houve diferença estatisticamente significante entre os grupos.

No $14^{\circ}$ dia de pós-operatório, observou-se que a área cirúrgica apresentava crosta de consistência firme, de natureza fibrinoleucocitária, com escassa ou quase nenhuma substância hialinizada, o que coincide com os achados de Alvares $^{16}$, Marchini et al. ${ }^{6}$ e Sanchez Neto et al. ${ }^{5}$. A substância hialinizada é produzida pelo fibroblasto no tecido de granulação e é composta por mucopolissacarídeos, que estão envolvidos com a produção e orientação das fibras colágenas ${ }^{10}$. Em seguida inicia-se a fase proliferativa ou de fibroplasia. Em torno de quatro dias, estas células predominam no tecido de granulação em desenvolvimento. A densidade dos fibroblastos alcançam o máximo entre sete $\mathrm{e}$ 14 dias após a injúria, sob a influência de potentes fatores de crescimento da ferida ${ }^{18}$. Neste trabalho os valores obtidos na contagem de fibroblastos no $14^{\circ}$ dia de pós-operatório mostraram, tanto para o grupo Controle como para o Passiflora, que os valores começaram a decrescer, em consonância com os resultados obtidos por Alvares ${ }^{16}$ e Simões et al. ${ }^{13}$. Quando os dois grupos foram comparados entre si, não houve diferença estatisticamente significante ${ }^{17}$.

Em relação ao colágeno, os valores foram significantemente maiores aos 14 e 21 dias de pós-operatório do que aos sete dias, tanto para o grupo Controle quanto para o Passiflora. Quando compararam-se os dois grupos entre si, houve aumento significativo no Passiflora $(\mathrm{p}=0,01)$, sugerindo benefício do seu uso quando mensurado por este parâmetro.

No $21^{\circ}$ dia de pós-operatório, tanto o grupo Controle quanto o Passilflora apresentavam lesões totalmente epitelizadas. Modolin ${ }^{15}$ relataram que uma das características da última fase do processo de reparação tecidual (fase de maturação) é a regressão endotelial. Observou-se fenômeno semelhante no presente estudo, tanto no grupo Controle como no Passiflora. Nesta fase ocorre a epitelização da lesão, que é controlada por complexo glicoprotéico denominado chalona, e que estimula a atividade mitótica epitelial ${ }^{16}$. Nas observações morfológicas, não foram encontradas diferenças entre os epitélios das lesões do grupo Controle e do Passiflora ${ }^{18}$.

\section{Perspectivas futuras}

O emprego do extrato de Passiflora edulis no processo de cicatrização de feridas cutâneas em seres humanos permanece ainda campo aberto a estudos, no entanto é importante que se amplie o estudo experimental em animais com dosagens maiores, maior números de dias de experimentação, além do isolamento do componente ou componentes do extrato, responsáveis pela influência positiva no processo de reparação de tecidos.

Enfim, os resultados do presente estudo permitem concluir que o uso tópico do extrato de Passiflora edulis não apresenta efeito significativo na cicatrização da pele de ratos em relação à área cirúrgica. Entretanto, o uso tópico do extrato de Passiflora edulis associa-se a aumento da proliferação fibroblástica e melhor reepitelização no $7^{\circ}$ dia de pós-operatório, e reação inflamatória leucocitária e colagenização mais intensa no $14^{\circ}$ dia de pós-operatório, sugerindo efeito benéfico do processo cicatricial.

\section{Referências}

1. Carrico TJ, Mehrhof AI Jr., Cohen IK. Biology of wound healing. Surg Clin North Am. 1984; 4(4):721-33.

2. Banks WJ. Histologia veterinária aplicada. São Paulo: Manole; 1992.

3. Contrera A, Bernardi AC, Pozetti GL, Lopes RA, Contrera MGD. Ação da tintura-mãe de Lichnophora ericoides, Aristolochia esperanzae e Solidago microglossa, em feridas cutâneas de ratos. Rev Esc Farm Odont. 1985; 11: $157-60$. 
4. Gottrup F. Healing of incisional wounds in stomach and duodenum. A biomechanical study. Am J Surg. 1980; 140(2):296-301.

5. Sanchez Neto R, Barone B, Teves DC, Simões MJ, Novo NF, Juliano Y. Aspectos morfológicos e morfométricos da reparação tecidual de feridas cutâneas de ratos com e sem tratamento com solução de papaína a 2 por cento. Acta Cir Bras. 1993 8(1):18-23.

6. Marchini FB, Martins DMFS, Teves DC, Simões MJ. Efeito do óleo de rosa mosqueta na cicatrização de feridas abertas. Rev. paul. med 1988; 106(6):356.

7. Eurides D, Mazzanti A, Belleti ME, Silva LAF, Fioravante MCS. Morfologia e morfometria da reparação tecidual de feridas cutâneas de camundongos tratadas com solução aquosa de barbatimão. Rev Fac Zootec Vet Agro, Uruguaiana 1996; 2/3(1):35-40.

8. Brito NMB. Aspectos morfológicos e morfométricos da cicatrização de feridas cutâneas abertas em ratos tratados com óleo de copaíba. [Dissertação - Mestrado].São Paulo: Universidade Federal de São Paulo;1996.

9. Miranda LTGS. Uso da tintura de Arnica em feridas cutâneas abertas em ratos. [Dissertação - Mestrado] São Paulo: Universidade Federal de São Paulo, Escola Paulista de Medicina; 2001.

10. Auersvald A. Estudo comparativo do efeitos induzidos pela aplicação do laser de $\mathrm{CO} 2$ e do laser de Erbium: Yttrium Aluminum Garnet, em pele de ratos. 2001. [Dissertação - Mestrado] Curitiba: Instituto de Pesquisas Médicas, Faculdade Evangélica do Paraná; 2001.
11. Silva BTF. Estudos farmacológicos da Passiflora edulis. [Dissertação - Mestrado]. São Luis: Universidade Federal do Maranhão; 1998.

12. Silva BTF, Nunes FLC, Freire SMF. Efeito antiinflamatório, analgésico e antipirético do extrato etanólico de folha de Passiflora edulis var flavicarpa (maracujá amarelo) Cad Pesqui. 2001; 11.

13. Simões MJ, Cabral ACV, Boyaciyan K, Kulay Jr I, Sasso WS. Aspectos ultraestruturais dos fibroblastos e dos macrófagos durante o processo de reparação da pele de ratos. Rev Paul Med1986;104(3):132-5

14. Gemperli R, Faria JCM, Costa MP. Cicatrização In: Ferreira, MC, editor. Condutas de cirurgia plástica para o cirurgião geral. São Paulo: Rober; 1995.

15. Modolin M, Bevilacqua RG,Ruy G. Cicatrização das feridas. Síntese das aquisições recentes. Rev Bras Clin Terap 1985;14(6):208-13.

16. Alvares S. Contribuição para o estudo histométrico e histoquímico do processo de reparação de lesões obtidas experimentalmente na pele de ratos albinos. [Tese - Doutorado]. São Paulo: Universidade de São Paulo:, Faculdade de Odontologia; 1972.

17. Junqueira LC, Carneiro J. Histologia básica. Rio de Janeiro: Guanabara Koogan, 1999.

18. Masini E, Calamo MA. Uma forma de tratamento de lesões cutâneas com papaína e sacarose. Rev Bras Clin Terap. 1986; 15(8):245-8.

\section{Correspondência:}

Antonio Carlos Ligocki Campos

Rua Comendador Araujo, 143, cj 113

80420-000 Curitiba - PR
Conflito de interesses: nenhum Fonte de financiamento: Capes

Recebimento: 18/02/2005

Revisão: 08/06/2005

Aprovação: 13/06/2006

\section{Como citar este artigo:}

Garros IC, Campos ACL, Tâmbara EM, Tenório SB, Torres OJM, Agulham MA, Araújo ACF, Sains-Isolan PMB, Oliveira EM, Arruda ECM. extrato de Passiflora edulis na cicatrização de feridas cutâneas abertas em ratos: estudo morfológico e histológico. Acta Cir Bras. [periódico na internet] 2006;21 Supl 3:55-65. Disponível em URL: http://www.scielo.br/acb

*Figuras coloridas disponíveis em www.scielo.br/acb 